\title{
Questes
}

vestes Revue pluridisciplinaire d'études médiévales

\section{Les manifestations divines : conclusion}

\section{Céline Ménager et Isabelle Coumert}

\section{OpenEdition}

\section{Journals}

Édition électronique

URL : http://journals.openedition.org/questes/1158

DOI : 10.4000/questes. 1158

ISSN : 2109-9472

\section{Éditeur}

Les Amis de Questes

\section{Édition imprimée}

Date de publication : 15 septembre 2010

Pagination : 105-108

ISSN : 2102-7188

\section{Référence électronique}

Céline Ménager et Isabelle Coumert, «Les manifestations divines : conclusion », Questes [En ligne], 19| 2010, mis en ligne le 01 janvier 2014, consulté le 19 septembre 2020. URL : http://

journals.openedition.org/questes/1158; DOI : https://doi.org/10.4000/questes. 1158 


\section{Conclusion}

\section{Céline MenAGER et Isabelle COUMERT}

Les manifestations divines se révèlent, dans leurs modalités, d'une diversité extrême. En effet leur acteur principal peut être Dieu lui-même, le Christ, un ange ou des personnages saints, anonymes ou célèbres, considérés comme ses émissaires, au premier rang desquels la Vierge occupe une place privilégiée ; la manifestation en soi peut relever d'une simple apparition, du miracle défiant les lois de la nature, ou de l'action beaucoup plus indirecte d'une Providence masquée dont les desseins ne se révèlent qu'au vrai croyant. Limitée dans le temps comme dans le nombre de ses témoins mortels, elle laisse un héritage ambigu, objet tantôt de célébration, tantôt d'interrogation sur sa nature véritable, et déborde souvent le domaine de la foi pour devenir argument politique.

Le Moyen Âge s'est interrogé sur la façon dont se déroule une manifestation divine, et la réponse proposée semble être double.

La liturgie paraît souvent déterminante pour permettre de recréer un espace sacré, et avec lui des conditions propices à une intervention de Dieu. C'est ainsi que les apparitions du Graal s'accompagnent d'un rituel étroitement codifié (Isabelle Coumert), ou que le culte de saint Michel prépare ses intercessions par le culte des reliques issues des précédents miracles de l'Archange (Bruno Varennes) ${ }^{1}$. Le sacré s'accompagne de rituels réactualisant les événements anciens, qu'il s'agisse de miracles ou d'épisodes de la vie du Christ. En rupture avec une conception linéaire de

\footnotetext{
${ }^{1}$ S'il n'existe bien entendu pas de reliques physiques de l'archange, en revanche le culte de saint Michel s'organise autour de reliques humaines liées à ses manifestations et miracles.
} 
l'Histoire, la manifestation divine ainsi commémorée et suscitée renvoie à une représentation cyclique de la temporalité, garantie par le rite.

Mais l'intervention divine peut aussi se faire spontanément, sans nulle intervention humaine et sans nul miracle pour la rendre évidente: ainsi la bataille de l'Auray est-elle immédiatement interprétée comme l'œuvre de la Providence, en dehors de tout événement spectaculaire. Pour Guillaume de Saint-André, la victoire devient le signe d'une élection divine ; à travers elle, Dieu a fait savoir qu'il choisissait Jean de Montfort comme duc de Bretagne, au détriment de son rival Charles de Blois (David Dominé-Cohn).

Dès lors, les manifestations divines apparaissent comme les deux facettes du rapport entre l'homme et Dieu : ce dernier peut être appelé par des prières et des rites aussi bien que se manifester de son propre chef, d'une manière aussi explicite que dans les miracles ou les lettres de Dieu (Fanny Oudin), ou encore de manière beaucoup plus discrète, imperceptible, au point que repérer son action relève alors d'un pur acte de foi. Peu à peu, c'est cette seconde vision des choses qui l'emportera, contribuant au « désenchantement » du monde ${ }^{2}$.

Loin d'avoir une approche purement naïve ou contemplative des épiphanies du sacré, le Moyen Âge s'interroge à travers elles sur les desseins de Dieu: pourquoi ce dernier recherche-t-il le contact avec l'humanité ? Pour transmettre un message, ou pour agir directement icibas? Souvent les deux desseins se confondent. La manifestation divine

\footnotetext{
${ }^{2}$ Cette expression, dont la paternité est attribuée au sociologue allemand Max Weber (1864-1920), renvoie au phénomène social de recul des croyances religieuses ou magiques comme modalités d'explication des phénomènes. Le recul progressif des interventions divines spectaculaires au profit d'actions plus ambiguës de la Providence - actions susceptibles de se confondre avec le seul hasard ou même avec l'Histoire en son ensemble - nous semble y participer. Voir les travaux de Marcel GAUCHET, Le Désenchantement du monde. Une histoire politique de la religion, Paris, Gallimard, « Bibliothèque des sciences humaines », 1985.
} 
assume fréquemment une fonction protectrice, comme dans le cas des miracles du culte de saint Michel. Elle désigne des élus ou des saints par la faveur insigne qu'elle représente. Elle permet l'extase mystique qui élève à une compréhension supérieure de la réalité, dans le cas du Graal. Elle peut aussi revêtir une fonction pastorale dans les lettres de Dieu, ou exercer une influence politique décisive, comme lorsque la Providence choisit son camp dans la succession de Bretagne. Les interventions divines dressent ainsi le portrait d'un Dieu très actif dans l'Histoire humaine, soucieux d'approuver, de désapprouver, de protéger ou de punir, de récompenser ou d'insuffler l'espoir, de guider ou d'envoyer en mission.

Les manifestations divines peuvent être globalement considérées comme des substituts à l'Incarnation; par là même, elles demeureront, intrinsèquement, décevantes. Incomplètes par essence, elles ne seront que des signes imparfaits destinés à rappeler l'action efficace de la Providence dans l'Histoire, ou à faire connaître la volonté divine. La manifestation divine pose ainsi un double problème de représentation et d'interprétation ; un problème de mimesis, si l'on se place du point de vue du narrateur, le sublime visé dépassant les faibles moyens de l'homme et de l'écriture. Faut-il suggérer le mystère, assumer les lacunes - renoncer à plonger son regard dans le Graal ? Ou bien, au contraire, s'efforcer de rendre accessible un message aussi simple que celui des Évangiles, un message pragmatique, directement efficace, ici et maintenant, au risque de compromettre sa dimension sacrée? Mais se pose aussi un problème, plus crucial encore, d'interprétation ; à travers la manifestation divine, c'est en effet la volonté divine qui se manifeste - et qui sera en mesure de l'interpréter de manière univoque ? N'y a-t-il pas toujours un espace laissé à la compréhension personnelle, et par là à l'erreur humaine ? N'est-il pas tentant de «faire parler » les signes, de les réinventer, jusqu'à en faire un usage politique à 
son profit? La question de l'imposture se pose très tôt, comme le prouvent les débats sur les apocryphes ou sur l'origine des lettres divines.

Les manifestations divines s'inscrivent donc, sous tous ces aspects, dans le difficile dialogue entre le Créateur et ses créatures. Longtemps la distinction entre l'immuabilité des lois naturelles, la mobilité des intentions humaines et l'éternité des desseins providentiels n'a en effet guère fait débat: l'idée que Dieu recherchait à exercer une action efficace dans l'histoire humaine, que la Providence était dotée d'un projet à l'échelle de l'humanité semblait bien établie. À la fin du Moyen Âge cependant, des réflexions philosophiques comparables à celles de Giordano Bruno viennent battre en brèche ce postulat en identifiant Dieu et la Nature comme une seule et même substance (Marion Lieutaud). C'est alors la légitimité même de l'idée d'un dialogue entre la créature et Dieu, voire d'une volonté divine distincte du flux des événements qui est remise en question. Dès lors, la manifestation divine se vide de sens et de raison d'être : elle est nulle part et partout. 